\title{
TOTAL EXCHANGEABLE SODIUM, TOTAL EXCHANGEABLE POTASSIUM, AND TOTAL BODY WATER IN EDEMA- TOUS PATIENTS WITH CIRRHOSIS OF THE LIVER AND CONGESTIVE HEART FAILURE ${ }^{1}$
}

\author{
By L. W. BIRKENFELD,² J. LEIBMAN, ${ }^{3}$ M. P. O'MEARA,4 AND I. S. EDELMAN 5 \\ (From the Department of Medicine, University of California School of Medicine, and the San \\ Francisco Hospital, San Francisco, Calif.)
}

(Submitted for publication November 7, 1957 ; accepted January 13, 1958)

The application of isotope-dilution methods to the study of body composition has provided accurate in vivo estimates of the amount of body sodium, potassium, chloride, water, and fat in normal human subjects of both sexes at many age levels (1-10). Similar studies in a variety of disease states have shown changes in body composition characterized by decreases in body fat, cell mass, and body potassium, and increases in body sodium and water, when these values are expressed on a body weight basis (11-16). While this pattern of change in composition is apparent in chronically ill or acutely stressed patients who are free of edema, it is particularly pronounced in edematous subjects $(13,14,16-18)$. These studies, however, have not indicated whether there are changes in the proportions of body sodium, potassium, and water which are specific for a disease state. Recently, Farber and Soberman (19) noted that edematous patients with heart disease have less body water and a higher ratio of exchangeable sodium to body water than edematous patients with hepatic or renal disease. They suggested that heart failure invokes an increase in body sodium content out of proportion to the gain of extracellular water. Similar comparative stud-

1 This work was financed by grant-in-aid support from the American Heart Association, the United States Public Health Service (Grant No. H-1441), the San Francisco Heart Association, the Paul and Susan Gardiner Fund, and the Medical Research Committee of the University of California School of Medicine, San Francisco, Calif.

2 Research Fellow of the National Heart Institute, United States Public Health Service.

${ }^{3}$ Research Fellow of the San Francisco Heart Association.

4 Research Fellow of the National Heart Institute, United States Public Health Service.

5 Established Investigator of the American Heart Association. ies with respect to body potassium have not yet been reported, although low values have been noted in chronically ill patients with and without edema $(15,16,18,20-23)$. The lack of a practical method for estimating body fat, however, makes it difficult to decide whether these findings represent a loss of cell mass or a decrease in the proportion of potassium to cell mass.

These studies need to be extended because of difficulties in quantitating and interpreting changes in body composition in edematous patients. It has recently been shown that equilibrium of isotope distribution may be delayed in edematous subjects (18). The variations of body composition with sex $(5,8,16)$, age $(5,7,8,24,25)$, nutrition $(5,7,12,16)$, and treatment $(15,19,22,26)$ make it important to assure that changes ascribed to a disease are not a reflection of some of these other factors.

The objectives of the present investigation were to compare total exchangeable sodium $\left(\mathrm{Na}_{\mathrm{e}}\right)$, total exchangeable potassium $\left(\mathrm{K}_{\mathrm{e}}\right)$, and total body water (T.B.W.) in patients with edema due to congestive heart failure and in patients with edema due to cirrhosis of the liver, to add information on differences in body composition in edematous and edema-free patients, and to clarify the interpretation of changes in body potassium content.

Sodium ${ }^{24}, \mathrm{~K}^{42}$ and $\mathrm{D}_{2} \mathrm{O}$ were used as tracers in this study, and the findings are expressed as $\mathrm{Na}_{\mathrm{e}} /$ T.B.W., $\mathrm{K}_{\mathrm{e}} / \mathrm{T}$.B.W., $\mathrm{Na}_{\mathrm{e}} / \mathrm{K}_{\mathrm{e}}, \mathrm{Na}_{\mathrm{e}}$ /“dry" body weight, and $\mathrm{K}_{\mathrm{e}}$ /"dry" body weight, as well as the usual expressions per unit of body weight. The results failed to confirm a disproportional increase in body sodium or a higher ratio of body sodium to body water $\left(\mathrm{Na}_{\mathrm{e}} / \mathrm{T}\right.$.B.W. $)$ in patients with congestive heart failure compared with patients with cirrhosis of the liver. However, distinct differences in body composition were found 
TABLE I

Clinical data-Males

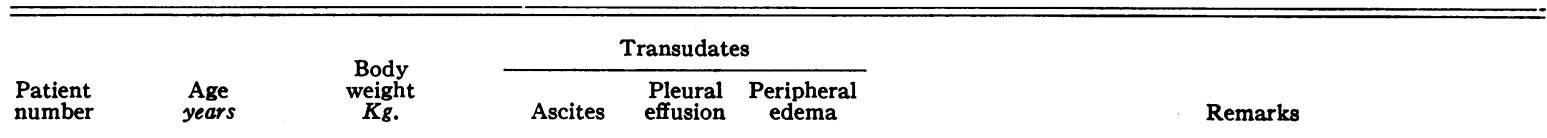

Group I. Cirrhosis of liver-edema

$\begin{array}{rrrl}+4 & 0 & +1 & \text { icterus } \\ +1 & 0 & +1 & \begin{array}{l}\text { icterus } \\ +3\end{array} \\ +3 & 0 & 0 & \text { liver biopsy, portal cirrhosis } \\ +4 & 0 & +1 & \text { icterus; autopsy, portal cirrhosis } \\ +2 & 0 & 0 & \text { esophageal varices } \\ +3 & 0 & 0 & \\ +3 & 0 & 0 & \text { liver biopsy, portal cirrhosis } \\ +2 & 0 & 0 & \text { liver biopsy, portal cirrhosis } \\ +3 & 0 & +4 & \text { icterus } \\ +4 & 0 & +2 & \text { icterus } \\ +2 & 0 & +2 & \text { icterus } \\ +2 & 0 & 0 & \text { icterus; hepatic coma } \\ +2 & 0 & +1 & \text { icterus } \\ +3 & 0 & +1 & \text { icterus; liver biopsy, portal cirrhosis } \\ +1 & 0 & +1 & \text { icterus } \\ +3 & 0 & +2 & \end{array}$

$\begin{array}{lll}\text { Mean } & 52.2 & 69.7\end{array}$

Range $\quad 39-74 \quad 50.9-101.3$

Group II. Congestive heart failure -edema

\begin{tabular}{|c|c|c|c|c|c|c|}
\hline $\begin{array}{r}1 \\
5 \\
10 \\
11 \\
12 \\
18 \\
25 \\
26 \\
37 \\
47 \\
51 \\
61 \\
75 \\
78 \\
90 \\
93\end{array}$ & $\begin{array}{l}64 \\
64 \\
66 \\
76 \\
68 \\
55 \\
67 . \\
58 \\
79 \\
54 \\
84 \\
71 \\
66 \\
40 \\
60 \\
74\end{array}$ & $\begin{array}{r}64.1 \\
53.9 \\
119.5 \\
80.0 \\
59.8 \\
41.8 \\
47.7 \\
75.8 \\
62.3 \\
48.6 \\
56.4 \\
58.0 \\
53.6 \\
71.4 \\
53.2 \\
65.9\end{array}$ & $\begin{array}{r}0 \\
0 \\
+4 \\
0 \\
0 \\
0 \\
0 \\
0 \\
0 \\
0 \\
0 \\
0 \\
0 \\
0 \\
+3 \\
+2\end{array}$ & $\begin{array}{r}+1 \\
+1 \\
0 \\
0 \\
0 \\
0 \\
0 \\
+1 \\
0 \\
0 \\
0 \\
0 \\
0 \\
0 \\
0 \\
0\end{array}$ & $\begin{array}{l}+1 \\
+1 \\
+4 \\
+2 \\
+1 \\
+1 \\
+1 \\
+3 \\
+1 \\
+2 \\
+2 \\
+2 \\
+2 \\
+2 \\
+4 \\
+2\end{array}$ & $\begin{array}{l}\text { hypertensive and arteriosclerotic heart disease } \\
\text { hypertensive and arteriosclerotic heart disease } \\
\text { arteriosclerotic heart disease } \\
\text { hypertensive and arteriosclerotic heart disease } \\
\text { arteriosclerotic heart disease } \\
\text { cor pulmonale } \\
\text { arteriosclerotic heart disease } \\
\text { hypertensive and arteriosclerotic heart disease } \\
\text { hypertensive and arteriosclerotic heart disease } \\
\text { hypertensive cardiovascular disease } \\
\text { arteriosclerotic heart disease } \\
\text { arteriosclerotic heart disease } \\
\text { heart disease of unknown type } \\
\text { hypertensive cardiovascular disease } \\
\text { hypertensive cardiovascular disease } \\
\text { arteriosclerotic heart disease }\end{array}$ \\
\hline $\begin{array}{l}\text { Mean } \\
\text { Range }\end{array}$ & $\begin{array}{c}65.4 \\
40-84\end{array}$ & $\begin{array}{c}63.3 \\
47.7-119.5\end{array}$ & & & & \\
\hline \multicolumn{7}{|c|}{ Group III. } \\
\hline $\begin{array}{l}4 \\
9 \\
14 \\
15 \\
31 \\
34 \\
41 \\
45 \\
49 \mathrm{a} \\
76\end{array}$ & $\begin{array}{l}68 \\
45 \\
67 \\
72 \\
69 \\
90 \\
73 \\
74 \\
33 \\
62\end{array}$ & $\begin{array}{l}86.9 \\
69.2 \\
59.5 \\
59.3 \\
48.0 \\
43.6 \\
60.5 \\
57.0 \\
44.0 \\
62.5\end{array}$ & $\begin{array}{l}0 \\
0 \\
0 \\
0 \\
0 \\
0 \\
0 \\
0 \\
0 \\
0\end{array}$ & $\begin{array}{l}\mathbf{0} \\
0 \\
0 \\
0 \\
0 \\
0 \\
0 \\
0 \\
0 \\
0\end{array}$ & $\begin{array}{l}\mathbf{0} \\
\mathbf{0} \\
\mathbf{0} \\
\mathbf{0} \\
\mathbf{0} \\
\mathbf{0} \\
\mathbf{0} \\
\mathbf{0} \\
\mathbf{0} \\
\mathbf{0}\end{array}$ & $\begin{array}{l}\text { benign gastric ulcer } \\
\text { duodenal ulcer } \\
\text { abscesses of wrist and elbow } \\
\text { cellulitis of arm and leg } \\
\text { pulmonary emphysema } \\
\text { generalized arteriosclerosis } \\
\text { cerebrovascular accident } \\
\text { anemia and purpura } \\
\text { pulmonary tuberculosis } \\
\text { panhypopituitarism }\end{array}$ \\
\hline $\begin{array}{l}\text { Mean } \\
\text { Range }\end{array}$ & $\begin{array}{c}65.3 \\
33-90\end{array}$ & $\begin{array}{c}59.1 \\
43.6-86.9\end{array}$ & & & & \\
\hline \multicolumn{7}{|c|}{ Group IV. Patients with heart disease-previously edematous } \\
\hline $\begin{array}{l}21 \\
42 \\
52\end{array}$ & $\begin{array}{l}60 \\
71 \\
70\end{array}$ & $\begin{array}{l}59.8 \\
44.8 \\
50.9\end{array}$ & $\begin{array}{l}\mathbf{0} \\
\mathbf{0} \\
\mathbf{0}\end{array}$ & $\begin{array}{l}\mathbf{0} \\
\mathbf{0} \\
\mathbf{0}\end{array}$ & $\begin{array}{l}\mathbf{0} \\
\mathbf{0} \\
\mathbf{0}\end{array}$ & $\begin{array}{l}\text { cor pulmonale } \\
\text { cor pulmonale } \\
\text { heart disease of unknown type }\end{array}$ \\
\hline $\begin{array}{l}\text { Mean } \\
\text { Range }\end{array}$ & $\begin{array}{c}67.3 \\
60-71\end{array}$ & $\begin{array}{c}51.8 \\
44.8-59.8\end{array}$ & & & & \\
\hline
\end{tabular}


TABLE II

Clinical data-Females

\begin{tabular}{|c|c|c|c|c|c|c|}
\hline \multirow[b]{2}{*}{$\begin{array}{l}\text { Patient } \\
\text { number }\end{array}$} & \multirow[b]{2}{*}{$\begin{array}{c}\text { Age } \\
\text { years }\end{array}$} & \multirow{2}{*}{$\begin{array}{c}\text { Body } \\
\text { weight } \\
K \boldsymbol{K g} .\end{array}$} & \multicolumn{3}{|c|}{ Transudates } & \multirow[b]{2}{*}{ Remarks } \\
\hline & & & Ascites & $\begin{array}{c}\text { Pleural } \\
\text { effusion }\end{array}$ & $\begin{array}{c}\text { Peripheral } \\
\text { edema }\end{array}$ & \\
\hline \multicolumn{7}{|c|}{ Group V. Cirrhosis of liver-edema } \\
\hline $\begin{array}{l}19 \\
22 \\
35 \\
44 b \\
50\end{array}$ & $\begin{array}{l}28 \\
37 \\
43 \\
43 \\
39\end{array}$ & $\begin{array}{l}39.6 \\
39.8 \\
51.8 \\
56.8 \\
65.7\end{array}$ & $\begin{array}{l}+1 \\
+1 \\
+3 \\
+3 \\
+3\end{array}$ & $\begin{array}{l}0 \\
0 \\
0 \\
0 \\
0\end{array}$ & $\begin{array}{l}\mathbf{0} \\
\mathbf{0} \\
\mathbf{0} \\
\mathbf{0} \\
\mathbf{0}\end{array}$ & $\begin{array}{l}\text { icterus } \\
\text { icterus } \\
\text { icterus; liver biopsy, portal cirrhosis } \\
\text { icterus; autopsy, portal cirrhosis }\end{array}$ \\
\hline $\begin{array}{l}\text { Mean } \\
\text { Range }\end{array}$ & $\begin{array}{c}38 \\
28-43\end{array}$ & $\begin{array}{c}50.7 \\
39.6-65.7\end{array}$ & & & & . \\
\hline \multicolumn{7}{|c|}{ Group VI. Congestive heart failure-edema } \\
\hline $\begin{array}{l}7 \\
23 \\
49 b \\
80\end{array}$ & $\begin{array}{l}67 \\
51 \\
86 \\
82\end{array}$ & $\begin{array}{l}85.0 \\
55.2 \\
51.8 \\
63.6\end{array}$ & $\begin{array}{l}\mathbf{0} \\
\mathbf{0} \\
\mathbf{0} \\
\mathbf{0}\end{array}$ & $\begin{array}{l}0 \\
0 \\
0 \\
0\end{array}$ & $\begin{array}{l}+3 \\
+2 \\
+1 \\
+1\end{array}$ & $\begin{array}{l}\text { arteriosclerotic heart disease } \\
\text { cor pulmonale } \\
\text { hypertensive and arteriosclerotic heart disease } \\
\text { arteriosclerotic heart disease }\end{array}$ \\
\hline $\begin{array}{l}\text { Mean } \\
\text { Range }\end{array}$ & $\begin{array}{c}72 \\
51-86\end{array}$ & $\begin{array}{c}63.9 \\
51.8-85.0\end{array}$ & & & & \\
\hline \multicolumn{7}{|c|}{ Group VII. Hospitalized "controls"—no edema } \\
\hline $\begin{array}{l}40 \\
39 \\
72\end{array}$ & $\begin{array}{l}78 \\
28 \\
77\end{array}$ & $\begin{array}{l}41.4 \\
36.4 \\
43.2\end{array}$ & $\begin{array}{l}\mathbf{0} \\
\mathbf{0} \\
\mathbf{0}\end{array}$ & $\begin{array}{l}\mathbf{0} \\
\mathbf{0} \\
\mathbf{0}\end{array}$ & $\begin{array}{l}\mathbf{0} \\
\mathbf{0} \\
\mathbf{0}\end{array}$ & $\begin{array}{l}\text { cerebrovascular accident } \\
\text { adrenal insufficiency } \\
\text { subdural hematoma, postoperative }\end{array}$ \\
\hline $\begin{array}{l}\text { Mean } \\
\text { Range }\end{array}$ & $\begin{array}{c}61 \\
28-78\end{array}$ & $\begin{array}{c}40.3 \\
36.4-43.2\end{array}$ & & & & \\
\hline
\end{tabular}

between edematous and edema-free patients, and all patients differed significantly from normal subjects in all three categories of body composition.

\section{SUBJECTS AND METHODS}

Subjects. Fifty-seven patients were studied. They were divided into the following groups for purposes of comparison:

Group I: Sixteen edematous males with cirrhosis of the liver.

Group II: Sixteen edematous males with congestive heart failure.

Group III : Ten nonedematous male hospitalized "controls."

Group IV: Three nonedematous males with heart disease who had been edematous.

Group V: Five edematous females with cirrhosis of the liver.

Group VI: Four edematous females with congestive heart failure.

Group VII: Three nonedematous female hospitalized "controls."

Only subjects in whom an unequivocal diagnosis could be made by clinical and laboratory criteria were included for study. All patients received the customary treatment for their disease up to the week of study. The period of hospitalization, duration of treatment and loss of weight prior to the time of study were similar in the subjects with edema of cardiac and hepatic origin. The hospitalized "control" group consisted of patients without either heart disease or cirrhosis of the liver who had never been edematous. All patients were fed an analyzed diet containing $10 \mathrm{mEq}$. of sodium and $28 \mathrm{mEq}$. of potassium per 24 hours for at least one day prior to and the three days of study. Diuretics were withheld during the period of study. Food and fluid were withheld for the six hour period of $\mathrm{D}_{2} \mathrm{O}$ equilibration.

Methods. All isotopes were administered intravenously from calibrated syringes. Three hundred $\mu \mathrm{c}$. of $\mathrm{K}^{\mathrm{s}}$ was administered in the afternoon of the first day of study. Thirty-six to 40 hours later, following a complete voiding, two consecutive spot urine specimens were collected over a three to six hour interval. Catheterization was used when necessary to ensure complete urine collection. At the time of the first spot. urine collection, 45 to 100 $\mathrm{ml}$. of 99.5 per cent $\mathrm{D}_{2} \mathrm{O}$ was injected. Four and onehalf and six hours later, venous blood was collected for deuterium, sodium, and potassium analyses; $150 \mu \mathrm{c}$. of $\mathrm{Na}^{24}$ was then injected. Venous samples for $\mathrm{Na}^{24}$ assay were collected 23 and 24 hours later.

The analytic procedures for chemical and radioactive assay have been described in detail (18). Potassium was counted with an end-window Geiger-Müller tube, and $\mathrm{Na}^{2}$ with a well-type sodium iodide scintillation counter. Serum collected just prior to $\mathrm{Na}^{24}$ injection was counted as a blank correction for residual $\mathrm{K}^{22}$ at the time of 
radiosodium assay; this correction was less than 2 per cent in all cases. $\mathrm{D}_{2} \mathrm{O}$ concentrations were determined in triplicate on each specimen by the falling drop method. Loss of $\mathrm{D}_{2} \mathrm{O}$ was calculated as 0.16 per cent of the injected dose per hour (18).

Calculations. Standard formulas were used in calculating specific activities, $\mathrm{Na}_{e}, \mathrm{~K}_{e}$, and T.B.W. (1). Zero time was taken to be the time at which the final equilibration samples for $K_{0}$ and T.B.W. were obtained. "Dry" body weight was calculated by subtracting the measured T.B.W. from the patient's body weight at zero time. Back correction of the measured $\mathrm{Na}_{\text {e }}$ to zero time was accomplished by metabolic balance from the known diet and the urinary sodium excretion during the 24 hour period of $\mathrm{Na}^{24}$ equilibration.

\section{RESULTS}

To avoid systematic influences on body composition because of age, sex and clinical status, the patients were grouped as listed in Tables I and II. The three primary groups for this study are the male subjects in Groups I, II and III. Tables III through VII list all the body composition data and the derived ratios of $\mathrm{Na}_{\mathrm{e}}$ /T.B.W., $\mathrm{Na}_{\mathrm{e}}$ /"dry" body weight, $\mathrm{Na}_{\mathrm{e}} / \mathrm{K}_{\mathrm{e}}, \mathrm{K}_{\mathrm{e}} / \mathrm{T}$.B.W., and $\mathrm{K}_{\mathrm{e}} /$ "dry" body weight. The statistical summary for the male subjects in Group I (cirrhosis of the liver with edema), Group II (congestive heart failure with edema), and Group III (hospitalized "controls") is given in Table VIII.

\section{Total body water}

The mean values for T.B.W. as per cent of body weight for edematous males with cirrhosis of the liver and congestive heart failure were 58.6 and 62.9 per cent, respectively; these values were significantly greater than the mean of 54.6 per cent for male hospitalized "controls." The difference between the mean values in congestive heart failure and in cirrhosis of the liver is not statistically significant. Although the female subjects were few in number, the values for T.B.W. in those with heart failure average less than in those with cirrhosis of the liver (See Table VII). The three males with heart disease who were no longer edematous had the highest mean value for T.B.W. as per cent of body weight (See Table VI).

\section{Total exchangeable sodium}

In the edematous male patients with cirrhosis of the liver and those with congestive heart failure, mean values for $\mathrm{Na}_{\mathrm{e}}$ /body weight were $54.1 \mathrm{mEq}$. per $\mathrm{Kg}$. and $57.8 \mathrm{mEq}$. per $\mathrm{Kg}$., respectively,

TABLE III

Group I-Body composition in male patients with cirrhosis of liver and edema

\begin{tabular}{|c|c|c|c|c|c|c|c|c|c|c|c|c|c|c|}
\hline $\begin{array}{l}\text { Patient } \\
\text { number }\end{array}$ & $\begin{array}{c}\text { Serum } \\
\mathrm{Na} \\
m E q . / L .\end{array}$ & $\underset{K^{*}}{\underset{m E q . / L .}{\text { Serum }}}$ & T.B.W. & $\underset{\%}{\text { T.B.W. }} \underset{\text { Body wt. }}{ }$ & $\begin{array}{c}\text { "Dry" } \\
\text { body } \\
\text { wt.† } \\
K g .\end{array}$ & $\underset{m E q}{\mathrm{Na}_{0}}$ & $\begin{array}{c}\mathrm{Na}_{0} \\
\text { Bodywt. } \\
m E q . / K g .\end{array}$ & $\begin{array}{c}\mathrm{Na}_{\mathrm{o}} \\
\text { "Dry" } \\
\text { bodywt. } \\
\mathrm{mEq} . / \mathrm{Kg} .\end{array}$ & $\underset{m E q . / L}{\mathrm{Na}_{0}}$ & $\underset{m E q}{\mathrm{~K}_{0}}$ & $\begin{array}{c}\mathrm{K}_{\bullet} \\
\text { Body wt. } \\
m E q . / K g .\end{array}$ & $\begin{array}{c}\text { K. } \\
\text { "Dry" } \\
\text { bodywt. } \\
m E q . / K g .\end{array}$ & $\underset{m E q . / L}{\mathrm{~K}_{0}}$ & $\underset{m E q . / m E q}{\mathrm{Na}_{0} / \mathrm{K}_{\bullet}}$ \\
\hline 2 & 145.0 & 3.07 & 39.26 & 58.3 & 28.0 & 4,152 & 61.7 & 148.3 & 105.8 & 1,785 & 26.5 & 63.8 & 45.5 & 2.33 \\
\hline 3 & 144.7 & 3.91 & 43.11 & 53.9 & 36.9 & 3,541 & 44.3 & 96.0 & 82.1 & 3,205 & 40.1 & 86.9 & 74.3 & 1.10 \\
\hline 6 & 127.7 & 5.18 & 26.86 & 64.3 & 14.9 & 2,417 & 57.8 & 162.2 & 90.0 & 1,438 & 34.4 & 96.5 & 53.5 & 1.68 \\
\hline 16 & 139.9 & 3.19 & 50.14 & 49.5 & 51.2 & 5,153 & 50.9 & 100.6 & 102.8 & 2,350 & 23.2 & 45.9 & 46.9 & 2.19 \\
\hline 20 & 127.1 & 4.87 & 27.66 & 54.3 & 23.2 & 2,359 & 46.3 & 101.7 & 85.3 & 1,665 & 32.7 & 71.8 & 60.2 & 1.42 \\
\hline 24 & 133.0 & 3.89 & 37.43 & 55.9 & 29.6 & 3,511 & 52.4 & 118.6 & 93.8 & 2,140 & 31.9 & 72.3 & 57.2 & 1.64 \\
\hline 30 & 146.1 & 3.55 & 52.28 & 66.3 & 26.5 & 5,386 & 68.3 & 203.2 & 103.0 & 2,819 & 35.8 & 106.4 & 53.9 & 1.91 \\
\hline 66 & 150.2 & 4.33 & 32.57 & 58.7 & 22.9 & 3,085 & 55.6 & 134.7 & 94.7 & 1,816 & 32.7 & 79.3 & 55.8 & 1.70 \\
\hline 79 & 123.2 & 3.54 & 43.53 & 55.7 & 34.7 & 4,300 & 55.0 & 123.9 & 98.8 & 1,680 & 21.5 & 48.4 & 38.6 & 2.56 \\
\hline 81 & 143.4 & 3.94 & 52.09 & 64.0 & 29.3 & 5,510 & 67.7 & 188.1 & 105.8 & 2,308 & 28.4 & 78.8 & 44.3 & 2.39 \\
\hline 84 & 143.4 & 4.07 & 55.55 & 65.7 & 29.0 & 5,470 & 64.7 & 188.6 & 98.5 & 2,775 & 32.8 & 95.7 & 50.0 & 1.97 \\
\hline 87 & 125.7 & 3.52 & 40.01 & 52.1 & 36.8 & 2,852 & 37.1 & 77.5 & 71.3 & 2,521 & 32.8 & 68.5 & 63.0 & 1.13 \\
\hline 88 & 140.2 & 3.78 & 37.92 & 63.2 & 22.1 & 3,284 & 54.7 & 148.6 & 86.6 & 2,197 & 36.6 & 99.4 & 57.9 & 1.49 \\
\hline 89 & 135.5 & 3.94 & 35.62 & 52.6 & 32.1 & 3,116 & 46.0 & 97.1 & 87.5 & 1,762 & 26.0 & 54.9 & 49.5 & 1.77 \\
\hline 91 & 143.3 & 4.27 & 38.33 & 59.9 & 25.7 & 3,308 & 51.7 & 128.7 & 86.3 & 2,415 & 37.7 & 94.0 & 63.0 & 1.37 \\
\hline 92 & 134.8 & 4.38 & 38.03 & 63.4 & 22.0 & 3,103 & 51.7 & 141.0 & 81.6 & 2,349 & 39.2 & 106.8 & 61.8 & 1.32 \\
\hline Mean & 137.7 & 3.91 & 40.65 & 58.6 & 29.1 & 3,784 & 54.1 & 134.9 & 92.1 & 2,202 & 32.0 & 79.3 & 54.7 & 1.75 \\
\hline S.D.f & & & & \pm 5.5 & & & \pm 8.6 & \pm 37.5 & \pm 10.0 & & \pm 5.5 & \pm 20.0 & \pm 8.9 & \pm 0.45 \\
\hline Range & $\begin{array}{l}123.2- \\
150.2\end{array}$ & $\begin{array}{l}3.07- \\
5.18\end{array}$ & $\begin{array}{l}26.86- \\
56.12\end{array}$ & & $\begin{array}{l}14.9- \\
51.2\end{array}$ & $\begin{array}{l}2,359- \\
5,510\end{array}$ & & & & $\begin{array}{l}1,665 \\
3,205\end{array}$ & & & & \\
\hline
\end{tabular}

* mEq. per liter of serum water.

$\dagger$ Body weight minus total body water.

†S.D. $=\sqrt{\frac{\sum(x-\bar{x})^{2}}{n-1}}$. 
TABLE IV

Group II-Body composition in male patients with congestive heart failure and edema

\begin{tabular}{|c|c|c|c|c|c|c|c|c|c|c|c|c|c|c|}
\hline $\begin{array}{l}\text { Patient } \\
\text { number }\end{array}$ & $\begin{array}{c}\text { Serum } \\
\mathrm{Na}^{*} \\
m E q . / L .\end{array}$ & 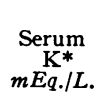 & T.B.W. & $\begin{array}{c}\text { T.B.W. } \\
\text { Body wt. }\end{array}$ & $\begin{array}{c}\text { “Dry”" } \\
\text { body } \\
\text { wt.† } \\
K g .\end{array}$ & $\begin{array}{c}\mathrm{Na}_{e} \\
m E q .\end{array}$ & 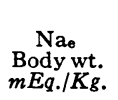 & $\begin{array}{c}\mathrm{Na} \\
\text { "Dry", } \\
\text { body wt. } \\
m E q . / K g .\end{array}$ & $\begin{array}{c}\mathrm{Na}_{e} \\
\mathrm{~T} . \mathrm{B} . \mathrm{W} \\
m E q . / L .\end{array}$ & $\underset{m E q}{\mathrm{~K}_{e}}$ & $\begin{array}{c}\mathrm{K}_{\bullet} \\
\text { Body wt. } \\
m E q . / K g .\end{array}$ & $\begin{array}{c}\text { Ke } \\
\text { "Dry" } \\
\text { bodywt. } \\
m E q . / K g .\end{array}$ & $\begin{array}{c}\mathrm{K}_{\text {o }} \\
\text { T.B.W. } \\
m E q . / L .\end{array}$ & $\underset{m E q . / m E q .}{\mathrm{Na}_{\mathrm{e}} / \mathrm{K}_{\mathrm{\theta}}}$ \\
\hline 1 & 154.5 & 4.55 & 34.05 & 53.1 & 30.0 & 3,122 & 48.7 & 104.1 & 91.7 & 2,454 & 38.3 & 81.8 & 72.1 & 1.27 \\
\hline 5 & 141.8 & 4.61 & 33.78 & 62.7 & 20.1 & 3,189 & 59.2 & 158.7 & 94.4 & 1,963 & 36.4 & 97.7 & 58.1 & 1.62 \\
\hline 10 & 148.0 & 4.74 & 69.64 & 58.3 & 49.9 & 6,983 & 58.4 & 139.9 & 100.3 & 3,293 & 27.6 & 66.0 & 47.3 & 2.12 \\
\hline 11 & 146.7 & 4.16 & 39.85 & 49.8 & 40.1 & 3,812 & 47.7 & 95.1 & 95.7 & 2,681 & 33.5 & 66.9 & 67.3 & 1.42 \\
\hline 12 & 129.2 & 4.88 & 35.00 & 58.5 & 24.8 & 2,359 & 39.4 & 95.1 & 67.4 & 2,599 & 43.5 & 104.7 & 74.3 & 0.91 \\
\hline 18 & 146.9 & 4.69 & 24.89 & 59.5 & 16.9 & 1,953 & 46.7 & 115.6 & 78.5 & 1,862 & 44.5 & 110.2 & 74.8 & 1.05 \\
\hline 25 & 146.2 & 4.13 & 30.91 & 64.8 & 16.8 & 3,113 & 65.3 & 185.3 & 100.7 & 1,665 & 34.9 & 99.1 & 53.9 & 1.87 \\
\hline 26 & 137.0 & 6.45 & 49.52 & 65.3 & 26.3 & 5,116 & 67.5 & 194.5 & 103.3 & 2,772 & 36.6 & 105.4 & 56.0 & 1.85 \\
\hline 37 & 145.1 & 4.65 & 32.41 & 52.0 & 29.9 & 2,971 & 47.7 & 99.4 & 91.7 & 1,986 & 31.9 & 66.4 & 61.3 & 1.50 \\
\hline 47 & 137.6 & 4.52 & 31.57 & 65.0 & 17.0 & 3,046 & 62.7 & 179.2 & 96.5 & 1,750 & 36.0 & 102.9 & 55.4 & 1.74 \\
\hline 51 & 119.5 & 4.74 & 36.78 & 65.2 & 19.6 & 3,385 & 60.0 & 172.7 & 92.0 & 1,424 & 25.2 & 72.7 & 38.7 & 2.38 \\
\hline 61 & 122.6 & 4.96 & 39.99 & 68.9 & 18.0 & 3,451 & 59.5 & 191.7 & 86.3 & 2,048 & 35.3 & 113.8 & 51.2 & 1.69 \\
\hline 75 & 125.3 & 5.88 & 38.87 & 72.5 & 14.7 & 3,659 & 68.3 & 248.9 & 94.1 & 1,699 & 31.7 & 115.6 & 43.7 & 2.15 \\
\hline 78 & 139.9 & 3.34 & 50.36 & 70.5 & 21.0 & 3,702 & 51.8 & 176.3 & 73.5 & 3,723 & 52.1 & 177.3 & 73.9 & 0.99 \\
\hline 90 & 138.5 & 4.25 & 36.34 & 68.3 & 16.9 & 3,733 & 70.2 & 220.9 & 102.7 & 1,571 & 29.5 & 93.0 & 43.2 & 2.38 \\
\hline 93 & 144.0 & 3.37 & 47.21 & 71.6 & 18.7 & 4,770 & 72.4 & 255.1 & 101.0 & 1,928 & 29.3 & 103.1 & 40.8 & 2.47 \\
\hline Mean & 138.9 & 4.62 & 39.45 & 62.9 & 23.8 & 3,648 & 57.8 & 164.5 & 91.9 & 2,214 & 35.4 & 98.5 & 57.0 & 1.71 \\
\hline S.D. & & & & \pm 7.0 & & & \pm 9.8 & \pm 49.5 & \pm 10.6 & & \pm 6.9 & \pm 27.2 & \pm 12.6 & \pm 0.51 \\
\hline Range & $\begin{array}{l}122.6- \\
154.5\end{array}$ & $\begin{array}{l}3.34- \\
6.45\end{array}$ & $\begin{array}{l}24.89- \\
69.64\end{array}$ & & $\begin{array}{l}14.7- \\
49.9\end{array}$ & $\begin{array}{l}1,953- \\
6,983\end{array}$ & & & & $\begin{array}{l}1,424- \\
3,723\end{array}$ & & & & \\
\hline
\end{tabular}

* mEq. per liter of serum water.

$\dagger$ Body weight minus total body water.

TABLE V

Group III-Body composition in male patients, hospitalized "controls"

\begin{tabular}{|c|c|c|c|c|c|c|c|c|c|c|c|c|c|c|}
\hline $\begin{array}{l}\text { Patient } \\
\text { number }\end{array}$ & $\begin{array}{c}\text { Serum } \\
\mathrm{Na} a^{*} \\
m E q . / L .\end{array}$ & $\underset{K^{*}}{\underset{\text { Serum }}{m E q . / L .}}$ & T.B.W. & $\begin{array}{c}\text { T.B.W. } \\
\text { Body wt. }\end{array}$ & $\begin{array}{c}\text { "Dry" } \\
\text { body } \\
\text { wt. } \\
K g .\end{array}$ & $\underset{m E q .}{\mathrm{Na}_{\mathbf{e}}}$ & $\begin{array}{c}\mathrm{Na}_{0} \\
\text { Body wt. } \\
m E q . / K g .\end{array}$ & $\begin{array}{c}\mathrm{Na}_{\mathrm{e}} \\
\text { "Dry" } \\
\text { bodywt. } \\
m E q . / K g .\end{array}$ & $\begin{array}{c}\mathrm{Na}_{e} \\
\text { T.B.W. } \\
m E q . / L\end{array}$ & $\underset{m E q .}{\mathrm{K}_{\mathbf{0}}}$ & $\begin{array}{c}\mathrm{K}_{0} \\
\text { Body wt. } \\
m E q . / K g .\end{array}$ & $\begin{array}{c}\mathrm{K}_{\mathrm{e}} \\
\text { "Dry" } \\
\text { body wt. } \\
m E q . / \mathrm{Kg} .\end{array}$ & $\begin{array}{c}\text { K॰ } \\
\text { T.B.W. } \\
m E q . / L .\end{array}$ & $\underset{m E q . / m E q}{\mathrm{Na}_{\mathrm{e}} / \mathrm{K}_{\bullet}}$ \\
\hline 4 & 146.3 & 4.41 & 43.79 & 50.4 & 43.1 & 3,511 & 40.4 & 81.5 & 80.2 & 3,427 & 39.4 & 79.5 & 78.3 & 1.03 \\
\hline 9 & 147.7 & 3.94 & 37.81 & 54.6 & 31.4 & 3,040 & 43.9 & 96.8 & 80.4 & 3,126 & 45.2 & 99.6 & 82.7 & 0.97 \\
\hline 14 & 146.3 & 4.32 & 30.15 & 50.7 & 29.3 & 2,624 & 44.1 & 89.6 & 87.0 & 2,040 & 34.3 & 69.6 & 67.7 & 1.28 \\
\hline 15 & 145.1 & 4.59 & 32.34 & 54.5 & 27.0 & 2,646 & 44.6 & 98.0 & 81.8 & 2,112 & 35.6 & 78.2 & 65.3 & 1.25 \\
\hline 31 & 145.3 & 5.21 & 27.83 & 58.0 & 20.2 & 2,257 & 47.0 & 111.7 & 81.1 & 2,105 & 43.9 & 104.2 & 75.6 & 1.07 \\
\hline 34 & 143.6 & 4.37 & 25.21 & 57.8 & 18.4 & 2,287 & 52.5 & 124.3 & 90.7 & 1,491 & 34.2 & 81.0 & 59.1 & 1.53 \\
\hline 41 & 132.2 & 4.45 & 29.85 & 49.3 & 30.6 & 2,446 & 40.4 & 79.9 & 81.9 & 1,805 & 29.8 & 59.0 & 60.5 & 1.36 \\
\hline 45 & 128.7 & 5.10 & 32.12 & 56.4 & 24.9 & 2,707 & 47.5 & 108.7 & 84.3 & 1,996 & 35.0 & 80.2 & 62.1 & 1.36 \\
\hline $49 a$ & 133.3 & 3.70 & 25.93 & 58.9 & 18.1 & 2,317 & 52.7 & 128.0 & 89.4 & 1,741 & 39.6 & 96.2 & 67.1 & 1.33 \\
\hline 76 & 134.1 & 4.62 & 34.38 & 55.0 & 28.1 & 2,645 & 42.3 & 94.1 & 76.9 & 2,180 & 34.9 & 77.6 & 63.4 & 1.21 \\
\hline Mean & 140.3 & 4.47 & 31.94 & 54.6 & 27.1 & 2,648 & 45.5 & 101.3 & 83.4 & 2,202 & 37.2 & 82.5 & 68.2 & 1.24 \\
\hline S.D. & & & & \pm 3.1 & & & \pm 4.1 & \pm 16.6 & \pm 4.5 & & \pm 4.8 & \pm 13.9 & \pm 8.0 & \pm 0.17 \\
\hline Range & $\begin{array}{l}128.7- \\
146.3\end{array}$ & $\begin{array}{l}3.94- \\
5.21\end{array}$ & $\begin{array}{l}25.21- \\
43.79\end{array}$ & & $\begin{array}{l}18.4- \\
43.1\end{array}$ & $\begin{array}{l}2,257- \\
3,511\end{array}$ & & & & $\begin{array}{l}1,491- \\
3,427\end{array}$ & & & & \\
\hline
\end{tabular}

* mEq. per liter of serum water.

$\dagger$ Body weight minus total body water.

TABLE VI

Group IV-Body composition in male patients with heart disease who were previously edematous

\begin{tabular}{|c|c|c|c|c|c|c|c|c|c|c|c|c|c|c|}
\hline $\begin{array}{l}\text { Patient } \\
\text { number }\end{array}$ & $\begin{array}{c}\text { Serum } \\
\mathrm{Na}^{*} \\
m E q . / L .\end{array}$ & 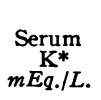 & $\underset{\text { T. }}{\text { T.W. }}$ & $\underset{\%}{\text { T.B.W. }} \underset{\text { Bodywt. }}{ }$ & $\begin{array}{c}\text { “Dry" } \\
\text { body } \\
\text { wt.† } \\
K g .\end{array}$ & $\underset{m E q}{\mathrm{Na}_{0}}$ & $\begin{array}{c}\mathrm{Na}_{\bullet} \\
\text { Body wt. } \\
m E q . / K g .\end{array}$ & $\begin{array}{c}\mathrm{Na}, \\
\text { "Dry" } \\
\text { body wt. } \\
m E q . / K g .\end{array}$ & $\begin{array}{c}\mathrm{Na}_{e} \\
\text { T.B.W. } \\
m E q . / L .\end{array}$ & $\underset{m E q}{\mathrm{~K}_{0}}$ & $\begin{array}{c}\mathrm{K}_{0} \\
\text { Bodywt. } \\
m E q . / K g .\end{array}$ & $\begin{array}{c}\text { Ko } \\
\text { "Dry" } \\
\text { bodywt. } \\
m E q . / K g .\end{array}$ & $\begin{array}{c}\mathrm{K}_{\mathbf{\theta}} \\
\text { T.B.W. } \\
m E q . / L .\end{array}$ & $\underset{m E q . / m E q .}{\mathrm{Na}_{e} / \mathrm{K}_{\odot}}$ \\
\hline 21 & 136.0 & 4.86 & 33.54 & 56.1 & 26.3 & 3,149 & 52.7 & 119.7 & 93.9 & 2,168 & 36.3 & 82.4 & 64.6 & 1.45 \\
\hline 42 & 131.8 & 4.35 & 29.75 & 66.4 & 15.0 & 2,495 & 55.7 & 166.3 & 83.9 & 1,650 & 36.8 & 110.0 & 55.5 & 1.51 \\
\hline 52 & 141.4 & 3.78 & 35.17 & 70.1 & 15.7 & 3,294 & 64.7 & 209.8 & 93.7 & 2,180 & 42.8 & 138.9 & 62.0 & 1.51 \\
\hline Mean & 136.4 & 4.33 & 32.82 & 64.2 & 19.0 & 2,979 & 57.7 & 165.3 & 90.5 & 1,999 & 38.6 & 110.4 & 60.7 & 1.49 \\
\hline Range & $\begin{array}{l}131.8- \\
141.4\end{array}$ & $\begin{array}{l}3.78- \\
4.86\end{array}$ & $\begin{array}{l}29.75- \\
35.17\end{array}$ & $\begin{array}{l}56.1- \\
70.1\end{array}$ & $\begin{array}{l}15.0- \\
26.3\end{array}$ & $\begin{array}{l}2,495- \\
3,294\end{array}$ & $\begin{array}{l}52.7- \\
64.7\end{array}$ & $\begin{array}{l}119.7- \\
209.8\end{array}$ & $\begin{array}{l}83.9- \\
93.9\end{array}$ & $\begin{array}{l}1,650- \\
2,180\end{array}$ & $\begin{array}{l}36.3- \\
42.8\end{array}$ & $\begin{array}{c}82.4- \\
138.9\end{array}$ & $\begin{array}{l}55.5- \\
64.6\end{array}$ & $\begin{array}{l}1.45- \\
1.51\end{array}$ \\
\hline
\end{tabular}

* mEq. per liter of serum water.

† Body weight minus total body water. 
both of which were significantly higher than the mean value of $45.5 \mathrm{mEq}$. per $\mathrm{Kg}$. in the "control" group (Tables III, IV, V and VIII and Figure 1). These findings confirm the relationship between edema formation and increased body sodium content (18). There is, however, no statistically impressive difference in $\mathrm{Na}_{e}$ /body weight between Groups I and II (cirrhosis and heart failure) (See Table VIII).

Exchangeable sodium was expressed per unit of "dry" body weight to eliminate the contribution of edema water to weight, and the following mean values were obtained: "controls," 101.3 mEq. per $\mathrm{Kg}$.; edematous male cirrhotics, 134.9 mEq. per Kg.; and edematous cardiacs, 164.5 $\mathrm{mEq}$. per $\mathrm{Kg}$. The values for each of the groups of edematous male patients differed significantly from those for the "controls." The $\mathrm{Na}_{\mathrm{e}}$ /"dry" body weight was higher in the male edematous subjects with heart failure than in the edematous subjects with cirrhosis, but because of the large standard deviations, statistical significance was not achieved.
The ratio of $\mathrm{Na}_{\mathrm{e}}$ to T.B.W. was calculated to evaluate whether there are disproportional changes in sodium content with edema formation in different diseases. The mean values for the ratio $\mathrm{Na}_{\mathrm{e}}$ /T.B.W. were $83.4 \mathrm{mEq}$. per L. for "controls," $92.1 \mathrm{mEq}$. per L. for edematous male cirrhotics, and $91.9 \mathrm{mEq}$. per L. for edematous male cardiacs. The difference between the "control" group and the edematous groups is probably significant. There is no difference between edematous male cardiacs and cirrhotics (see Tables III, IV, V and VIII and Figure 1). This ratio is of the same magnitude in the edematous female subjects and in the nonedematous patients with heart disease as in the edematous male subjects (see Tables VI and VII).

Expressing body sodium in proportion to "dry" weight or to body water takes into account the effect of variations in absolute water content on relative body sodium content, but these ratios do not reflect the proportion of sodium to the fat-free mass of the body. The $\mathrm{K}_{\mathrm{e}}$, however, may be an approximate index of lean body mass even in these seriously ill subjects. The ratio of $\mathrm{Na}_{e} / \mathrm{K}_{e}$ was

TABLE VII

Groups V,VI, VII-Body composition in female patients

\begin{tabular}{|c|c|c|c|c|c|c|c|c|c|c|c|c|c|c|}
\hline $\begin{array}{l}\text { Patient } \\
\text { number }\end{array}$ & $\begin{array}{c}\text { Serum } \\
\mathrm{Na}^{*} \\
m E q . / L .\end{array}$ & $\underset{\mathrm{K}^{*}}{\underset{m E q . / L}{\text { Serum }}}$ & $\begin{array}{c}\text { T.B.W. } \\
\text { L. }\end{array}$ & $\begin{array}{c}\text { T.B.W. } \\
\text { Body wt. }\end{array}$ & $\begin{array}{c}\text { “Dry" } \\
\text { body } \\
\text { wt. } \\
K g .\end{array}$ & $\underset{m E q}{\mathrm{Na}}$ & $\begin{array}{c}\mathrm{Na} \\
\text { Bodywt. } \\
m E q . / K g .\end{array}$ & $\begin{array}{c}\text { Nae } \\
\text { "Dry" } \\
\text { body wt. } \\
m E q . / K g .\end{array}$ & $\begin{array}{c}\mathrm{Na}_{\circ} \\
\text { T.B.W.W. } \\
m E q . L .\end{array}$ & $\underset{m E q}{\mathrm{~K}_{e}}$ & $\underset{m E q . / K g .}{\mathrm{K}_{\bullet}}$ & $\begin{array}{c}\text { Ko } \\
\text { "Dry", } \\
\text { bodywt. } \\
m E q . / K g .\end{array}$ & $\underset{m E q . / L .}{\mathrm{K}_{\bullet}}$ & $\underset{m E q . / m E q}{\mathrm{Na}_{\odot} / \mathrm{K}_{\bullet}}$ \\
\hline \multicolumn{15}{|c|}{ Group V. Cirrhosis of liver-edema } \\
\hline 19 & 138.6 & 3.68 & 22.69 & 57.3 & 16.9 & 2,228 & 56.3 & 131.8 & 98.2 & 1,203 & 30.4 & 71.2 & 53.0 & 1.85 \\
\hline 22 & 140.4 & 4.02 & 22.01 & 55.3 & 17.8 & 1,995 & 50.1 & 112.1 & 90.6 & 1,266 & 31.8 & 71.1 & 57.5 & 1.58 \\
\hline 35 & 138.2 & 4.41 & 35.52 & 68.6 & 16.3 & 3,772 & 72.8 & 231.4 & 106.2 & 1,525 & 29.4 & 93.6 & 42.9 & 2.47 \\
\hline $44 b$ & 130.7 & 3.90 & 32.55 & 57.3 & 24.2 & 2,941 & 51.8 & 121.5 & 90.4 & 1,683 & 29.6 & 69.5 & 51.7 & 1.74 \\
\hline 50 & 138.7 & 3.24 & 36.00 & 54.8 & 29.7 & 3,376 & 51.4 & 113.7 & 93.8 & 2,133 & 32.5 & 71.8 & 59.3 & 1.58 \\
\hline Mean & 137.3 & 3.85 & 29.75 & 58.7 & 21.0 & 2,862 & 56.5 & 142.1 & 95.8 & 1,562 & 30.7 & 75.4 & 52.9 & 1.84 \\
\hline Range & $\begin{array}{l}130.7- \\
140.4\end{array}$ & $\begin{array}{l}3.68- \\
4.41\end{array}$ & $\begin{array}{l}22.01- \\
36.00\end{array}$ & $\begin{array}{l}54.8- \\
68.6\end{array}$ & $\begin{array}{l}16.3- \\
29.7\end{array}$ & $\begin{array}{l}1,995- \\
3,376\end{array}$ & $\begin{array}{l}50.1- \\
72.8\end{array}$ & $\begin{array}{l}112.1- \\
231.4\end{array}$ & $\begin{array}{c}90.4- \\
106.2\end{array}$ & $\begin{array}{l}1,203- \\
2,133\end{array}$ & $\begin{array}{l}29.4- \\
32.5\end{array}$ & $\begin{array}{l}69.5- \\
93.6\end{array}$ & $\begin{array}{l}42.9- \\
59.3\end{array}$ & $\begin{array}{l}1.58- \\
2.47\end{array}$ \\
\hline \multicolumn{15}{|c|}{ Group VI. Congestive heart failure-edema } \\
\hline 7 & 152.1 & 4.00 & 44.77 & 52.7 & 40.2 & 4,876 & $\mathbf{5 7 . 4}$ & 121.3 & 108.9 & 1,936 & 22.7 & 48.2 & 43.2 & 2.52 \\
\hline 23 & 136.4 & 5.40 & 36.28 & 65.7 & 18.9 & 3,495 & 63.3 & 184.9 & 96.3 & 1,704 & 30.8 & 90.2 & 47.0 & 2.05 \\
\hline $49 \mathrm{~b}$ & 140.7 & 2.83 & 30.26 & 58.4 & 21.5 & 3,176 & 61.3 & 147.7 & 105.0 & 1,245 & 24.0 & 57.9 & 41.1 & 2.55 \\
\hline 80 & 122.2 & 4.88 & 23.99 & 37.7 & 39.0 & 1,957 & 30.7 & 50.2 & 81.6 & 1,164 & 18.3 & 29.8 & 48.5 & 1.68 \\
\hline Mean & 137.9 & 4.28 & 33.82 & 53.6 & 29.9 & 3,376 & 53.2 & 126.0 & 98.0 & 1,512 & 24.0 & 56.5 & 45.0 & 2.20 \\
\hline Range & $\begin{array}{l}122.2- \\
152.1\end{array}$ & $\begin{array}{l}2.83- \\
5.40\end{array}$ & $\begin{array}{l}23.99- \\
44.77\end{array}$ & $\begin{array}{l}37.7- \\
65.7\end{array}$ & $\begin{array}{l}18.9- \\
40.2\end{array}$ & $\begin{array}{l}1,957- \\
4,876\end{array}$ & $\begin{array}{l}30.7- \\
63.3\end{array}$ & $\begin{array}{c}50.2- \\
184.9\end{array}$ & $\begin{array}{c}81.6- \\
108.9\end{array}$ & $\begin{array}{l}1,164- \\
1,936\end{array}$ & $\begin{array}{l}18.3- \\
30.8\end{array}$ & $\begin{array}{l}29.8- \\
90.2\end{array}$ & $\begin{array}{l}41.1- \\
48.5\end{array}$ & $\begin{array}{l}1.68- \\
2.55\end{array}$ \\
\hline \multicolumn{15}{|c|}{ Group VII. Hospitalized "controls"—no edema } \\
\hline 40 & 143.0 & 3.62 & 22.20 & 53.6 & 19.2 & 2,146 & 51.8 & 111.8 & 96.7 & 1,218 & 29.4 & 63.4 & 54.9 & 1.76 \\
\hline 39 & 137.6 & 4.10 & 17.97 & 49.4 & 18.4 & 1,228 & 33.7 & 66.7 & 68.3 & 1,358 & 37.3 & 73.8 & 75.6 & 0.90 \\
\hline 72 & 134.9 & 4.06 & 25.95 & 60.1 & 17.2 & 2,110 & 48.8 & 122.7 & 81.3 & 1,667 & 38.5 & 96.9 & 64.2 & 1.27 \\
\hline Mean & 138.5 & 3.93 & 22.04 & 54.4 & 18.3 & 1,828 & 44.8 & 100.4 & 82.1 & 1,414 & 35.1 & 78.0 & 64.9 & 1.31 \\
\hline Range & $\begin{array}{l}134.9- \\
143.0\end{array}$ & $\begin{array}{l}3.62- \\
4.10\end{array}$ & $\begin{array}{l}17.97- \\
25.95\end{array}$ & $\begin{array}{l}49.4- \\
60.1\end{array}$ & $\begin{array}{l}17.2- \\
19.2\end{array}$ & $\begin{array}{l}1,228- \\
2,146\end{array}$ & $\begin{array}{l}33.7- \\
51.8\end{array}$ & $\begin{array}{l}66.7- \\
122.7\end{array}$ & $\begin{array}{l}68.3- \\
96.7\end{array}$ & $\begin{array}{l}1,218- \\
1,667\end{array}$ & $\begin{array}{l}29.4- \\
38.5\end{array}$ & $\begin{array}{l}63.4- \\
96.9\end{array}$ & $\begin{array}{l}54.9- \\
75.6\end{array}$ & $\begin{array}{l}0.90- \\
1.76\end{array}$ \\
\hline
\end{tabular}

* mEq. per liter of serum water.

$\dagger$ Body weight minus total body water. 
TABLE VIII

Statistical summary of body composition in edematous male patients with cirrhosis of the liver and congestive heart failure and in hospitalized "controls"

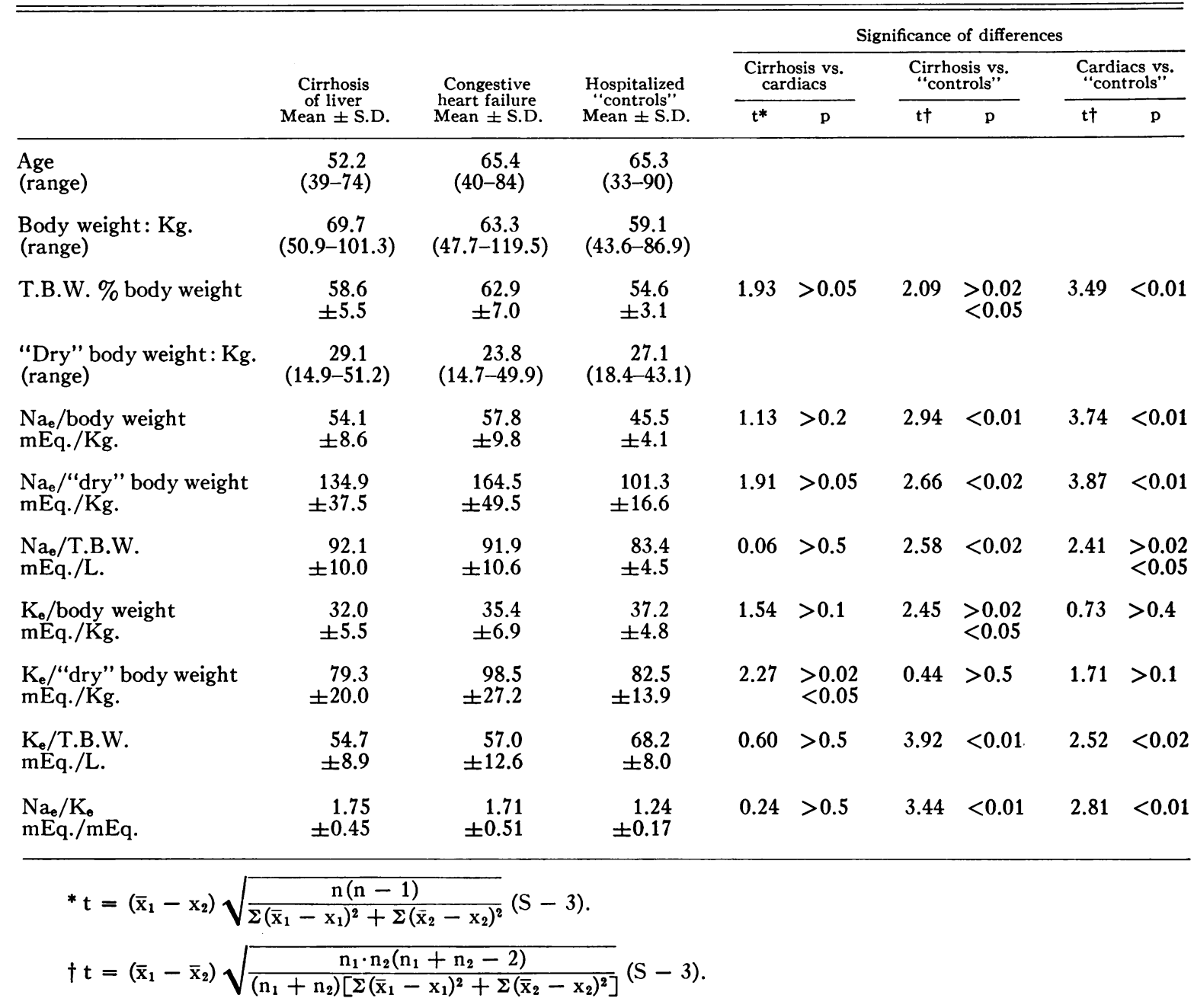

therefore calculated for each subject. The following mean values for the ratio of $\mathrm{Na}_{e} / \mathrm{K}_{e}$ were obtained : "controls," 1.24 ; male patients with edema and cirrhosis, 1.75; and edematous males with heart failure, 1.71. The values in the edematous patients differed significantly from those of the "control" group, but sodium content, when referred to an approximate measure of intracellular mass $\left(K_{e}\right)$, was similar in edematous subjects regardless of type of disease (see Table VIII and Figure 1). In the three subjects with heart disease without edema the $\mathrm{Na}_{e} / \mathrm{K}_{e}$ ratio was intermediate between the value for the edematous subjects and the value for the hospitalized "controls" (see Tables VI and VIII).

\section{Total exchangeable potassium}

The mean values for $\mathrm{K}_{\mathrm{e}}$ /body weight for Groups I, II, and III (cirrhotics, cardiacs, and "controls") were 32.0 , 35.4, and $37.2 \mathrm{mEq}$. per $\mathrm{Kg}$., respectively. Only the difference between the "controls" and the edematous cirrhotics approaches statistical significance $(0.05>\mathrm{p}>0.02)$ (see Table VIII). Nor are there any significant differences in $\mathrm{K}_{\mathrm{e}}$ per $\mathrm{Kg}$. of "dry" body weight between the edematous male subjects and the hospitalized "controls." The higher value in the edematous male cardiacs compared with that in the edematous male cirrhotics is of borderline significance, and the female subjects show an opposite trend (see 


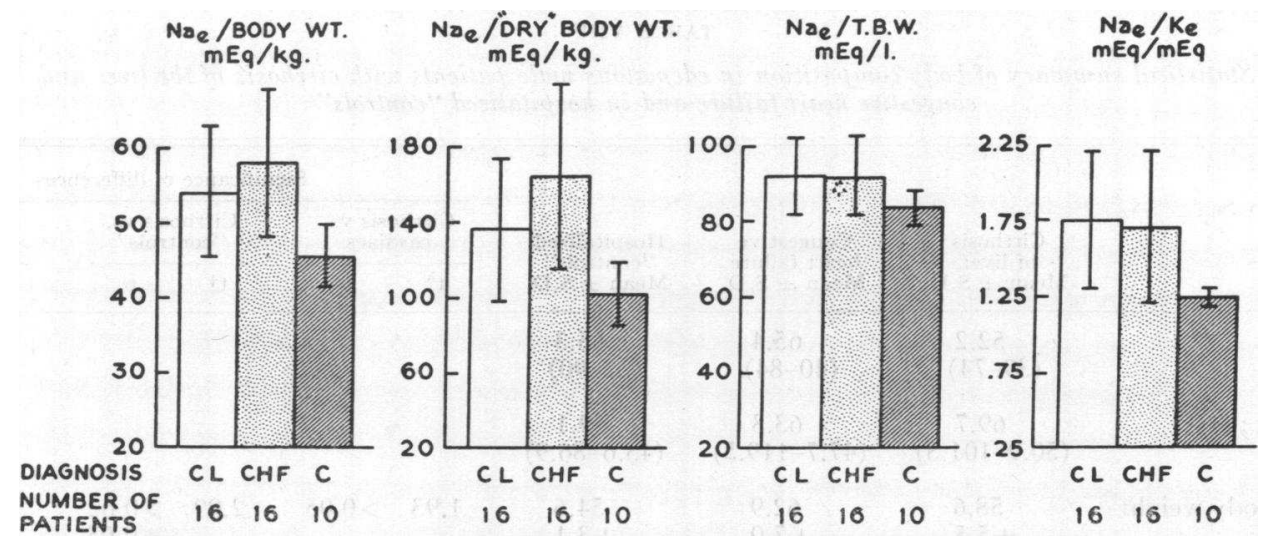

Fig. 1. Comparison of Na. in Edematous Male Patients with Cirrhosis of the Liver and Congestive Heart Failure and in Hospitalized "Controls"

The mean $\mathrm{Na}_{0}$ is depicted by the height of the bar, and the length of the line is equal to twice the standard deviation. The $\mathrm{Na}_{0}$ is expressed as $\mathrm{mEq}$. per $\mathrm{Kg}$. of body weight, $\mathrm{mEq}$. per $\mathrm{Kg}$.

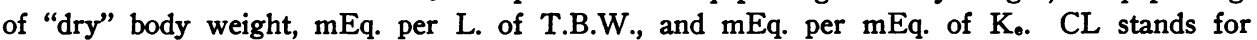
cirrhosis of the liver, CHF for congestive heart failure, and C for hospitalized "controls."

Tables VII and VIII). The values for $\mathrm{K}_{\mathrm{e}} /$ "dry" body weight in the male subjects with heart disease but without edema also were high (see Table VI). Since the ratio of $K_{e}$ to "dry" body weight reflects relative degrees of leanness as well as changes in potassium content, the latter findings probably indicate fat loss rather than conservation of potassium.

As one would expect, the ratio $\mathrm{K}_{\mathrm{e}} / \mathrm{T}$.B.W. was significantly lower in patients with edema than in nonedematous subjects. The mean values for the $\mathrm{K}_{\mathrm{e}} / \mathrm{T}$.B.W. ratio were 68.2 for "controls," 54.7 for edematous male cirrhotics, and 57.0 for edematous male cardiacs. The edematous groups differed significantly from the "controls," but not from each other (see Tables III, IV, V, and VIII and Figure 2). The results were the same in the female subjects (see Table VII). Indeed, these results reflect largely the diluting effect of overhydration on this ratio, and the reciprocal of this ratio $\left(\mathrm{K}_{\mathrm{e}} / \mathrm{T} . \mathrm{B} . \mathrm{W}\right.$.) is probably a fairly accurate measure of the magnitude of edema formation. The similarity of this ratio in Groups I and II probably indicates similar proportions of overhydration with respect to potassium content in these subjects.

\section{DISCUSSION}

Figures 1 and 2 depict the data on body composition in the three primary groups of patients. The $\mathrm{Na}_{\mathrm{e}} / \mathrm{T}$.B.W. ratio in the edematous patients with congestive heart failure is no different from that in the edematous patients with cirrhosis of the liver. The $\mathrm{Na}_{\mathrm{e}}$ /body weight and the $\mathrm{Na}_{\mathrm{e}}$ /"dry" body weight in edematous cardiacs exceed the corresponding value in the patients with liver disease, but the difference is not statistically convincing $(p>0.05)$. There are, furthermore, strikingly similar differences in $\mathrm{K}_{\mathrm{e}}$ /body weight and $\mathrm{K}_{\mathrm{e}}$ /"dry" body weight between these two groups (see Table VIII and Figure 2). Although the higher $\mathrm{Na}_{\mathrm{e}}$ /body weight and $\mathrm{K}_{\mathrm{e}}$ /body weight in the cardiacs might reflect changes in electrolyte content characteristic of these disease states, it is far likelier that the patients with liver disease had a higher percentage of body fat which diluted these parameters of body composition, i.e., $\mathrm{Na}_{\mathrm{e}}$ and $K_{e}$ (see Table VIII). Edema formation appears, therefore, to be associated in these groups of subjects with similar changes in body composition, regardless of the type of disease. These results do not confirm the report of a lower body water content and a higher ratio of body sodium to body water in edematous subjects with heart disease than in edematous cirrhotics (19). Exchangeable sodium per $\mathrm{Kg}$. of "dry" body weight and per L. of body water is high in subjects with heart failure rendered edema free (see Table VI). The T.B.W./body weight and the ratio of $\mathrm{K}_{\mathbf{e}}$ to "dry" body weight are higher in these three subjects than in the "controls," while $\mathrm{K}_{\mathrm{e}} / \mathrm{T}$.B.W. is slightly lower (see Tables VI and VIII), which is 


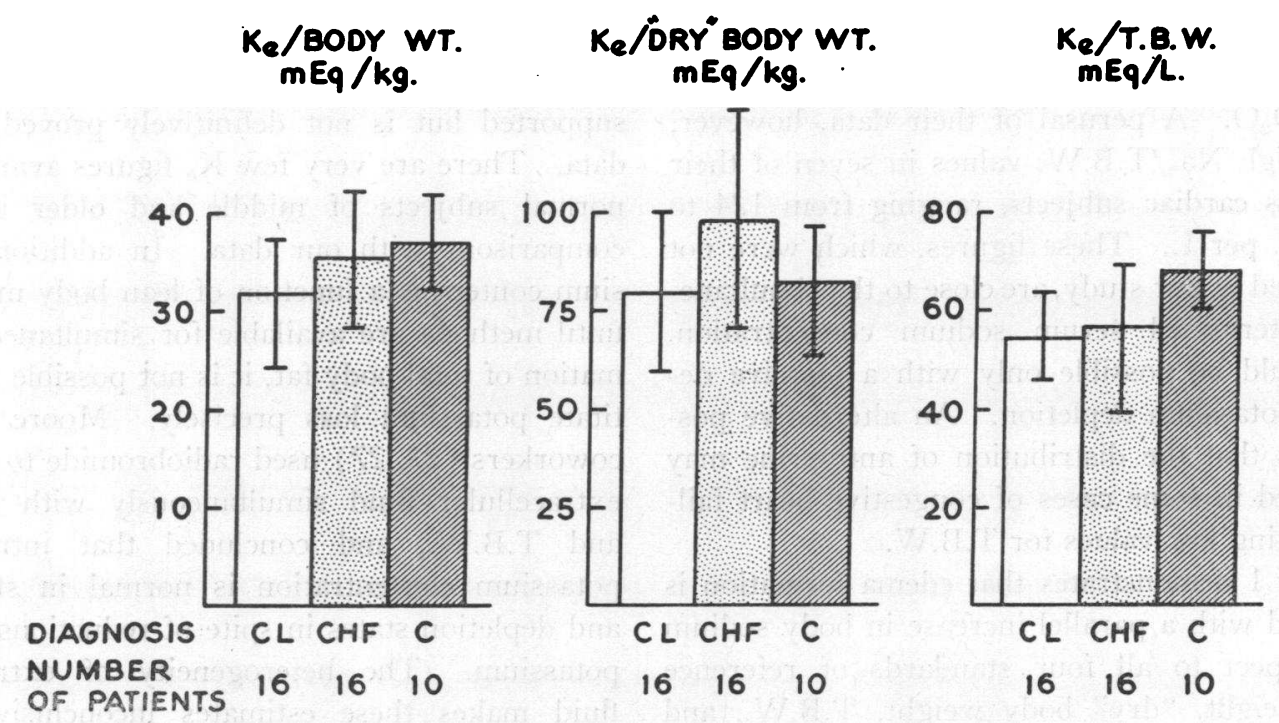

Fig. 2. Comparison of K. in Edematous Male Patients with Cirrhosis of the Liver and Congestive Heart Failure and in Hospitalized "Controls"

The mean $K_{0}$ is depicted by the height of the bar, and the length of the line is equal to twice the standard deviation. The $\mathrm{K}_{\mathbf{0}}$ is expressed as $\mathrm{mEq}$. per $\mathrm{Kg}$. of body weight, $\mathrm{mEq}$. per $\mathrm{Kg}$. of "dry" body weight, and mEq. per L. of T.B.W. The diagnostic symbols are the same as in Figure 1.

consistent with the previous conclusion that greater depletion of body fat, rather than selective accumulation of sodium, is involved in the process of heart failure.

The differences in the results obtained by us and those reported by Farber and Soberman (19) deserve some analysis. The $\mathrm{Na}_{\mathrm{e}}$ and T.B.W. data are summarized in Table IX. The results agree within 4 per cent except for the body water values and consequently the ratio of $\mathrm{Na}_{\mathrm{e}} / \mathrm{T}$.B.W. in the groups with heart failure. These discrepancies could arise from differences in patient populations (i.e., average fat content, influences of treatment, incidence of hyponatremia or amount of edema) or in methods of measurement. All our subjects had been treated and had long standing congestive heart failure; as a result fat content may have been lower. There is little difference in the mean and variance with respect to serum sodium concentration in the two groups [see Table IV (19) and Table IV, this paper]. While differences in the amount of edema in the two groups could account for differences in T.B.W., this would not explain the discrepancy in the $\mathrm{Na}_{\mathrm{e}} / \mathrm{T}$.B.W. ratio. Our results appear to be characteristic of the patient population with heart failure at this hospital since they are in agreement with those obtained previously (18). With respect to methods of

TABLE IX

Comparison of $\mathrm{Na}$ and total body water in patients with edema

\begin{tabular}{|c|c|c|c|c|c|c|c|c|}
\hline \multirow[b]{2}{*}{ Reference } & \multicolumn{4}{|c|}{ Congestive heart failure } & \multicolumn{4}{|c|}{ Cirrhosis of liver } \\
\hline & $\begin{array}{l}\text { Subjects } \\
\text { no. }\end{array}$ & $\begin{array}{c}\mathrm{Na}_{\odot} ! \\
\text { body weight } \\
m E q . / K g .\end{array}$ & $\begin{array}{c}\text { T.B.W./ } \\
\text { bodyeight } \\
\%\end{array}$ & $\begin{array}{c}\mathrm{Na}_{\mathrm{e}} / \mathrm{T} . \mathrm{B} . \mathrm{W} . \\
m E q . / L .\end{array}$ & $\begin{array}{l}\text { Subjects } \\
\text { no. }\end{array}$ & $\begin{array}{c}\mathrm{Na}_{0} / \\
\text { body weight } \\
m E q . / K g .\end{array}$ & $\begin{array}{c}\text { T.B.W./ } \\
\text { body weight } \\
\%\end{array}$ & $\begin{array}{c}\mathrm{Na}_{e} / \mathrm{T} . \mathrm{B} . \mathrm{W} \\
m E q . / L .\end{array}$ \\
\hline (19) & 50 & $\begin{array}{r}59.9 \\
\pm 11.0\end{array}$ & $\begin{array}{r}55.5 \\
\pm 7.5\end{array}$ & $\begin{array}{r}108.2 \\
\pm 12.0\end{array}$ & 16 & $\begin{array}{r}56.2 \\
\pm 9.3\end{array}$ & $\begin{array}{r}61.0 \\
\pm 7.2\end{array}$ & $\begin{array}{r}90.3 \\
\pm 11.6\end{array}$ \\
\hline This paper & 16 & $\begin{array}{r}57.8 \\
\pm 9.8\end{array}$ & $\begin{array}{r}62.9 \\
\pm 7.0\end{array}$ & $\begin{array}{r}91.9 \\
\pm 10.6\end{array}$ & 16 & $\begin{array}{r}54.1 \\
\pm 8.6\end{array}$ & $\begin{array}{r}58.6 \\
\pm 5.5\end{array}$ & $\begin{array}{r}92.1 \\
\pm 10.0\end{array}$ \\
\hline$\%$ difference & & -3.6 & +12.5 & -16.3 & & -3.8 & -4.0 & +2.0 \\
\hline
\end{tabular}


measurement, Farber and Soberman used antipyrine to estimate body water after checking against $\mathrm{D}_{2} \mathrm{O}$. A perusal of their data, however, reveals high $\mathrm{Na}_{\mathrm{e}} / \mathrm{T}$.B.W. values in seven of their edematous cardiac subjects, ranging from 124 to $140 \mathrm{mEq}$. per L. These figures, which were not approached in our study, are close to the simultaneously determined serum sodium concentration. This would be possible only with a massive degree of potassium depletion. An alternative possibility is that the distribution of antipyrine may be delayed in some cases of congestive heart failure, yielding low values for T.B.W.

Figure 1 demonstrates that edema formation is associated with a parallel increase in body sodium with respect to all four standards of reference (body weight, "dry" body weight, T.B.W., and $\mathrm{K}_{\mathrm{e}}$ ), which confirms the findings in many previous studies $(13,14,16,18,19,26)$. Body potassium was no lower in the patients with edema than in the hospitalized "controls" when the diluting effect of edema water was eliminated. The values for $\mathrm{K}_{\mathrm{e}}$ /body weight in these patients are in accord with those published previously $(11,15,16$, $20,22,23)$. Body potassium appeared to be abnormally low in all patient groups. The $\mathrm{K}_{\mathrm{e}} /$ "dry" body weight in young adult males calculated from the data of Corsa, Olney, Steenburg, Ball, and Moore (2) is $129 \pm 20 \mathrm{mEq}$. per Kg. ${ }^{6}$ and from the data of Ikkos, Ljunggren, Luft, and Sjögren (9) is $137 \pm 31 \mathrm{mEq}$. per $\mathrm{Kg}^{\circ}{ }^{6}$ These figures are significantly higher than the values of $80 \pm 20 \mathrm{mEq}$. per "dry" body weight ${ }^{7}$ in the male cirrhotics and $83 \pm 14 \mathrm{mEq}$. per "dry" body weight ${ }^{7}$ in the male hospitalized "controls" (see Table VIII). The female patients all showed similar decreases in body potassium (see Table VII). The near normal values of $99 \pm 27 \mathrm{mEq}$. per $\mathrm{Kg}$. "dry" body weight in the edematous cardiacs and $110 \pm 15 \mathrm{mEq}$. per $\mathrm{Kg}$. "dry" body weight ${ }^{7}$ in the nonedematous cardiacs probably reflect more advanced degrees of fat depletion rather than greater conservation of body potassium. Since disease is generally attended by loss of body fat, these figures relating body potassium to water-free body mass probably underestimate the degree of potassium depletion in all of these groups.

${ }^{6}$ Mean plus or minus one-fourth of range.
The conclusion that there is depletion of body potassium with chronic or debilitating disease is supported but is not definitively proved by our data. There are very few $\mathrm{K}_{\mathrm{e}}$ figures available for normal subjects of middle and older ages for comparisons with our data. In addition, potassium content is a function of lean body mass, and until methods are available for simultaneous estimation of total body fat, it is not possible to quantitate potassium loss precisely. Moore and his coworkers $(23,27)$ used radiobromide to estimate extracellular fluid simultaneously with $\mathrm{K}_{e}, \mathrm{Na}_{\mathrm{e}}$ and T.B.W., and concluded that intracellular potassium concentration is normal in starvation and depletion states in spite of reductions in body potassium. The heterogeneity of extracellular fluid makes these estimates inconclusive, however, since sodium and chloride are present in cells, transcellular fluid and dense connective tissues in varying quantities which have not yet been completely defined (28-32).

A clear distinction must be made between potassium depletion and potassium deficiency. The former refers to a decrease in potassium content per unit of lean body mass which may be an obligatory consequence of the disease process, since intracellular potassium accumulation is linked with cellular energy expenditure (32). In the latter case the cells are capable of accumulating potassium when it is provided in adequate quantities. Body composition studies alone do not, of course, enable one to make this distinction.

\section{SUMMARY}

Total exchangeable sodium, total exchangeable potassium and total body water were determined in nonedematous hospitalized "controls" and in edematous patients with cirrhosis of the liver and chronic congestive heart failure with the use of $\mathrm{Na}^{24}, \mathrm{~K}^{42}$ and $\mathrm{D}_{2} \mathrm{O}$ as tracers.

Total body water expressed as per cent of body weight is increased in edematous subjects; it averaged 58.6, 62.9 and 54.6 per cent in male subjects with edema and cirrhosis and with edema and heart failure, and in "controls," respectively.

Edema formation is associated with an increase in $\mathrm{Na}_{e}$ by all criteria (per unit body weight, per unit "dry" body weight, per liter of body water and per $\mathrm{mEq}$. of $\mathrm{K}_{\mathrm{e}}$ ). While the $\mathrm{Na}_{\mathrm{e}}$ /"dry" body weight was highest in the edematous cardiac 
group, no difference was found in the ratios of $\mathrm{Na}_{\mathrm{e}} / \mathrm{T} . \mathrm{B} . \mathrm{W}$. and $\mathrm{Na}_{\mathrm{e}} / \mathrm{K}_{\mathrm{e}}$ between edematous cirrhotic and edematous cardiac subjects. Selective or disproportionate accumulation of sodium with heart disease beyond that associated with edema formation was not demonstrated.

Exchangeable potassium was decreased below normal standards when referred to either body weight or "dry" body weight in all groups of patients. There was no difference in body potassium between edematous and nonedematous subjects when referred to "dry" body weight. Edematous male cardiacs had the highest $\mathrm{K}_{\mathrm{e}}$ /"dry" body weight, probably because total body fat was least in this group.

Limitations in interpretation of these data are discussed.

\section{ACKNOWLEDGMENT}

We wish to acknowledge with thanks the technical assistance of Mary Rose MacKerrow.

\section{REFERENCES}

1. Edelman, I. S., Olney, J. M., James, A. H., Brooks, L., and Moore, F. D. Body composition: Studies in the human being by the dilution principle. Science 1952, 115, 447.

2. Corsa, L., Jr., Olney, J. M., Jr., Steenburg, R. W., Ball, M. R., and Moore, F. D. The measurement of exchangeable potassium in man by isotope dilution. J. clin. Invest. 1950, 29, 1280.

3. Dunning, M. F., Steele, J. M., and Berger, E. Y. Measurement of total body chloride. Proc. Soc. exp. Biol. (N. Y.) 1951, 77, 854.

4. Aikawa, J. K., Harrell, G. T., and Eisenberg, B. The exchangeable potassium content of normal women. J. clin. Invest. 1952, 31, 367.

5. Edelman, I. S., Haley, H. B., Schloerb, P. R., Sheldon, D. B., Friis-Hansen, B. J., Stoll, G., and Moore, F. D. Further observations on total body water. I. Normal values throughout the life span. Surg. Gynec. Obstet. 1952, 95, 1.

6. Forbes, G. B., Reid, A., Bondurant, J., and Edtheridge, J. Estimation of total body chloride in young infants by radiobromide dilution. Proc. Soc. exp. Biol. (N. Y.) 1953, 83, 871.

7. Keys, A., and Brozek, J. Body fat in adult man. Physiol. Rev. 1953, 33, 245.

8. Edelman, I. S., James, A. H., Brooks, L., and Moore, F. D. Body sodium and potassium. IV. The normal total exchangeable sodium: Its measurement and magnitude. Metabolism 1954, 3, 530.

9. Ikkos, D., Ljunggren, H., Luft, R., and Sjögren, B. Content and distribution of potassium and chloride in adults. Metabolism 1955, 4, 231.
10. Friis-Hansen, B. Changes in body water compartments during growth. Acta paediat. (Uppsala) 1957, 46 (Suppl. 110), 1.

11. Aikawa, J. K., Felts, J. H., Jr., Tyor, M. P., and Harrell, G. T. The exchangeable potassium content in disease states. J. clin. Invest. 1952, 31, 743.

12. Moore, F. D., Haley, H. B., Bering, E. A., Brooks, L., and Edelman, I. S. Further observations on total body water. II. Changes of body composition in disease. Surg. Gynec. Obstet. 1952, 95, 155.

13. Warner, G. F., Dobson, E. L., Rodgers, C. E., Johnston, M. E., and Pace, N. The measurement of total "sodium space" and total body sodium in normal individuals and in patients with cardiac edema. Circulation 1952, 5, 915.

14. Warner, G. F., Sweet, N. J., and Dobson, E. L. "Sodium space" and body sodium content, exchangeable with sodium ${ }^{2 s}$ in normal individuals and patients with ascites. Circulat. Res. 1953, 1, 486.

15. Wilson, G. M., Edelman, I. S., Brooks, L., Myrden, J. A., Harken, D. E., and Moore, F. D. Metabolic changes associated with mitral valvuloplasty. Circulation 1954, 9, 199.

16. Moore, F. D., Edelman, I. S., Olney, J. M., James, A. H., Brooks, L., and Wilson, G. M. Body sodium and potassium. III. Inter-related trends in alimentary, renal and cardiovascular disease; lack of correlation between body stores and plasma concentration. Metabolism 1954, 3, 334.

17. Talso, P. J., Spafford, N., Ferenzi, G., and Jackson, H. O. Paradoxical hyponatremia associated with congestive heart failure and with cirrhosis of the liver. Metabolism 1956, 5, 58.

18. O'Meara, M. P., Birkenfeld, L. W., Gotch, F. A., and Edelman, I. S. The equilibration of radiosodium $\left(\mathrm{Na}^{24}\right)$, radiopotassium $\left(\mathrm{K}^{42}\right)$, and deuterium oxide $\left(\mathrm{D}_{2} \mathrm{O}\right)$ in hydropic human subjects. J. clin. Invest. 1957, 36, 784.

19. Farber, S. J., and Soberman, R. J. Total body water and total exchangeable sodium in edematous states due to cardiac, renal or hepatic disease. J. clin. Invest. 1956, 35, 779.

20. Aikawa, J. K., Felts, J. H., Jr., and Harrell, G. T., Jr. Alterations in the body potassium content in cirrhosis of the liver. Gastroenterology 1953, 24, 437.

21. Blainey, J. D., Cooke, W. T., Quinton, A., and Scott, $\mathrm{K}$. W. The measurement of total exchangeable potassium in man with particular reference to patients with steatorrhoea. Clin. Sci. 1954, 13, 165.

22. Aikawa, J. K., and Fitz, R. H. Exchangeable potassium content of the body in congestive heart failure. Changes during treatment. Circulation 1956, 14, 1093.

23. Moore, F. D., McMurrey, J. D., Parker, H. V., and Magnus, I. C. Body composition; total body wa- 
ter and electrolytes; intravascular and extravascular phase volumes. Metabolism 1956, 5, 447.

24. Friis-Hansen, B. J., Holiday, M., Stapleton, T., and Wallace, W. M. Total body water in children. Pediatrics 1951, 7, 321.

25. Forbes, G. B., and Perley, A. Éstimation of total body sodium by isotopic dilution. I. Studies on young adults. J. clin. Invest. 1951, 30, 558.

26. Aikawa, J. K., and Fitz, R. H. Alterations in exchangeable sodium content, "sodium ${ }^{24}$ space" and body weight during treatment of congestive failure. Circulation 1955, 12, 897.

27. McMurrey, J. D., Davis, J. M., Boling, E. A., and Moore, F. D. The evaluation of body composition in surgical disease processes utilizing a method for the simultaneous determination of red blood cell volume, plasma volume, blood volume, total body water, extracellular water and total exchangeable chloride, sodium and potassium. Surg. Forum 1955, 6, 14.

28. Nichols, G., Jr., Nichols, N., Weil, W. B., and Wallace, W. M. The direct measurement of the ex- tracellular phase of tissues. J. clin. Invest. 1953, 32, 1299.

29. Edelman, I. S., James, A. H., Baden, H., and Moore, F. D. Electrolyte composition of bone and the penetration of radiosodium and deuterium oxide into dog and human bone. J. clin. Invest. 1954, 33, 122.

30. Edelman, I. S., and Sweet, N. J. Gastrointestinal water and electrolytes. I. The equilibration of radiosodium in gastrointestinal contents and the proportion of exchangeable sodium $\left(\mathrm{Na}_{0}\right)$ in the gastrointestinal tract. J. clin. Invest. 1956, 35, 502.

31. Sweet, N. J., Nadell, J., and Edelman, I. S. Gastrointestinal water and electrolytes. III. The equilibration of radiobromide in gastrointestinal contents and the proportion of exchangeable chloride $\left(\mathrm{Cl}_{\mathrm{e}}\right)$ in the gastrointestinal tract. J. clin. Invest. 1957, 36, 279.

32. Conway, E. J. Nature and significance of concentration relations of potassium and sodium ions in skeletal muscle. Physiol. Rev. 1957, 37, 84. 